\title{
Functional characterization of Stagonospora nodorum necrotrophic effectors
}

\author{
S.V. Veselova*, G.F. Burkhanova, T.V. Nuzhnaya, I.V. Maksimov \\ Institute of Biochemistry and Genetics of the Ufa Federal Research Centre of the Russian Academy of Sciences, Ufa, Russia
}

DOI 10.18699/ICG-PlantGen2019-21

(c) Autors, 2019

* e-mail: veselova75@rambler.ru

\begin{abstract}
For many years pathogen causal agent of wheat leaf blotch such as Stagonospora nodorum have remained poorly understood, because the genetics of host resistance to S. nodorum in seedlings and adult plants is complex. The most important factor of virulence of the S. nodorum is multiple fungal necrotrophic effectors (NEs) encoded by SnTox genes that interact with the matching products of host susceptibility genes (Snn). In this mini-review, SnToxA-Tsn1, SnTox1-Snn1, and SnTox3-Snn3 interactions were described, including progress in the discovery of additional functions for effectors. The disclosure of the molecular mechanisms of action of necrotrophic effectors fundamentally changed our understanding of wheat leaf diseases.
\end{abstract}

Key words: Stagonospora nodorum; Triticum aestivum; necrotrophic effectors; wheat leaf diseases.

\section{Introduction}

The fungus Stagonospora nodorum is the causal agent of Septoria nodorum blotch (SNB) of wheat. SNB is a major disease of durum and common wheat in many parts of the world. Resistance to SNB has been shown to be a complex quantitatively inherited trait and, until recently, the underlying mechanism of virulence and resistance was not understood (Oliver et al., 2012; Faris et al., 2013; McDonald, Solomon, 2018). However, numerous recent studies to analyze wheat$S$. nodorum interactions have explained the genetic basis of this system at the classical and molecular levels. SNB is largely governed by a series of proteinaceous fungal necrotrophic effectors (NEs) (formerly referred to as host-specific (selective) toxins named SnToxN encoded by SnToxN genes), each of which interacts with a wheat susceptibility gene, $\operatorname{SnnN}$. These interactions lead to the formation of necrosis and/or chlorosis on wheat (McDonald, Solomon, 2018). In contrast to the classical gene-for-gene hypothesis, where the interaction of effectors with host resistance (R)-gene complexes leads to resistance, necrotrophic effectors function in an 'inverse' manner. An interaction between a necrotrophic effector and the product of a host dominant sensitivity gene instead leads to disease. The lack of NE recognition by the host leads to resistance. Therefore, these host-pathogen interactions operate in an inverse gene-for-gene manner and the dominant alleles of the host NE recognition genes are considered susceptibility genes (Oliver et al., 2012; Faris et al., 2013).

\section{Necrotrophic effectors of Stagonospora nodorum}

The wheat-S. nodorum pathosystem is mediated by multiple fungal necrotrophic effector-host sensitivity gene interactions that include SnToxA-Tsn1, SnTox1-Snn1, SnTox3-Snn3 and others. SnToxA encodes a 13.2-kDa mature protein that causes necrosis on wheat varieties that contain Tsn1 (Oliver et al., 2012; Shi et al., 2016). SnTox1 encodes a 10.3-kDa mature cysteine-rich protein with a chitin-like binding motif at the C-terminus. Sensitivity to SnTox1 is defined by the Snn1 gene located on wheat chromosome 1BS (Liu et al., 2012; Phan et al., 2016). Both Tsn1 and Snnl have been cloned and encode a serine/threonine protein kinase, nucleotide binding site leucine rich repeat protein (NB-LRR) and a wall-associated kinase protein (WAK), respectively (Shi et al., 2016; McDonald, Solomon, 2018). SnTox3 is an intron-free gene that codes for a $18-\mathrm{kDa}$ mature protein with six cysteine residues. SnTox3 is synthesized as a prepropeptide and cleavage of the signal peptide and the prosequence leads to maturation of a small, 17.5-kDa-long effector (Phan et al., 2016). Three disulfide bridges formed by six cysteine residues in SnTox3 are essential for the structure and function of the effector protein (Winterberg et al., 2014; Phan et al., 2016). Sensitivity to SnTox3 is conferred by Snn3-B1 and Snn3-D1 located on wheat chromosomes 5BS and 5DS, respectively (Phan et al., 2016). In addition, QTL analyses have revealed that the S. nodorum-wheat interaction includes multiple effector-host sensitivity gene interactions such as SnTox2-Snn2, SnTox4 Snn4 and SnTox5-Snn5, SnTox6-Snn6 and SnTox7-Snn7 (Oliver et al., 2012; Phan et al., 2016). Genes that code for these fungal effectors and host dominant susceptibility genes remained unidentified.

\section{SnTox1-Snn1}

The SnTox1-Snn1 interaction was the first interaction to be characterized. This interaction accounts for as much as $58 \%$ of the disease variation (Oliver et al., 2012). The mode of action of SnTox 1 is still under study. The SnTox $1-S n n 1$ interaction is light-dependent. Light is necessary for the penetration and proliferation of the pathogen (Shi et al., 2016). Recently, chitin binding activity for SnTox 1 has been visualized in vivo using a GFP-tagged version of the protein (Lui et al., 2012). It has been shown that SnTox1 binds to the surface of the hyphae particularly near the points of hyphal branching or plant penetration. Thus, chitin binding activity of SnTox1 was associated with the prevention of plant chitinases from binding with hyphae and degradation of the fungal cell wall and the release of chitin fragments into the apoplast. Consequently, the development of plant defense reactions was suppressed (Lui 
et al., 2012). In addition, it was shown that the SnTox1-Snn1 interaction caused the production of $\mathrm{H}_{2} \mathrm{O}_{2}$ and up-regulated transcription of genes of PR-protein and TaMAPK3 (Oliver et al., 2012; Shi et al., 2016).

\section{SnToxA-Tsn 1}

The SnToxA-Tsn1 interaction leading to necrosis was associated with photosynthesis. Expression of $T s n 1$ was regulated by the circadian clock and light, and the SnToxA-Tsn1 interaction was light-dependent (Oliver et al., 2012; McDonald, Solomon, 2018). Penetrating into the plant cell, SnToxA was located within the chloroplast and has been reported to bind to plastocyanin, a component of photosystem II, and a protein known as Tox-ABP1 (Oliver et al., 2012). The SnToxA-Tsn1 interaction results in photosystem perturbations leading to disruption of photosynthesis and cell death. Moreover, after SnToxA infiltration, a strong induction of secondary metabolism was observed, including tryptophan and monoamine serotonin. SnToxA strongly induced the tryptophan pathway as evident from microarray analysis.

Metabolome analysis detected significant increases in tryptophan, serotonin, two serotonin derivatives and the benzoxazinoid 6-methoxy-2-benzoxazolinone (MBOA) synthesized from the tryptophan precursor indole-3-glycerolphosphate (Fall et al., 2013). Recently. a novel role of serotonin as a phytoalexin in wheat has been established and it has been demonstrated that serotonin strongly inhibited sporulation of S. nodorum (Fall et al., 2013). Microscopy revealed that serotonin interferes with spore formation and maturation within pycnidial structures of the fungus. Subsequent analysis of $S$. nodorum exposed to serotonin revealed metabolite changes previously associated with sporulation, including trehalose and alternariol (Fall et al., 2013).

\section{SnTox3-Snn3}

The SnTox3-Snn3 interaction as well as the SnToxA-Tsn1 interaction led to the collapse of photosynthesis (Winterberg et al., 2014). It was interesting that they did so through different means. Thus, the SnTox3-Snn3 interaction did not depend on light. SnTox3 leads to down-regulation of the light reaction (particularly, photosystem I, ATP synthase) (Winterberg et al., 2014). In addition, SnTox3-infiltrated wheat leaves also showed a strong induction of enzymes involved in primary metabolism consistent with increases in hexoses, amino acids and organic acids as determined by primary metabolite profiling.

Careful scrutiny of both the microarray and proteomics data revealed impact on the secondary metabolism upon infiltration with SnTox3. Methionine and homocysteine metabolism was strongly induced upon exposure to SnTox3. Homocysteine S-methyltransferase, which catalyses synthesis of two methionine molecules from homocysteine and S-methyl methionine, was highly induced at the transcriptional level. Adenosylmethionine synthase, which catalyses the reaction from methionine to S-adenosyl methionine (SAM), responded positively at the transcriptional and the translational level upon SnTox 3 exposure. Genes encoding aminocyclopropane (ACC) synthase and ACC oxidase, both involved in the synthesis of ethylene from SAM, were up-regulated in SnTox3-infiltrated plants (Winterberg et al., 2014). SAM is a direct precursor for ethylene biosynthesis and primary methyl donor for a variety of defense-related metabolites.

Recently, by applying inhibitory analysis to different wheat genotypes and using $S$. nodorum isolates expressing SnTox3 (SnB) and not expressing SnTox3 (Sn4VD), we have shown that SnTox3 up-regulates the ethylene biosynthesis genes TaACS1, TaACO and genes for the primary response to ethylene, TaEIL1, TaPIE1 (TaERF1), through activation of genes of MPK3/MPK6 cascade and a significant increase of TaWRKY53b gene expression for regulating of redox-status of infected plants (Veselova et al., 2017; 2018a).

Furthermore, an inhibitory analysis showed that the ethylene signalling pathway activated by SnTox3 negatively affected the reactive oxygen species (ROS) generation in infected wheat plants at the initial stage of pathogen development (24 hour) (Veselova et al., 2018b). As a result of the ethylene influence on the enzymes of the pro- and antioxidant system, $\mathrm{O}_{2}{ }^{--}$content was reduced, and $\mathrm{H}_{2} \mathrm{O}_{2}$ generation was suppressed. Microscopy revealed that ethylene suppressing the oxidative burst at the pathogen penetration site provided appropriate conditions for the development of the pathogen in the wheat tissues (Veselova et al., 2018b).

\section{New functions of necrotrophic effectors}

The members of the pathogenesis-related protein 1 (PR-1) family are among the most abundantly produced proteins in plants on pathogen attack, and $P R-1$ gene expression has long been used as a marker for salicylic acid (SA)- dependent disease resistance. However, despite significant interest shown to them over several decades, their role in plant defense remains poorly understood. Recently, it has been shown that PR-1 proteins own sterol-binding activity, contain an embedded defense signaling peptide, CAPE1, and are targeted by effectors of plant pathogens during host infection (Breen et al., 2017). It has been shown that SnToxA and SnTox3 directly interact with the PR-1 protein (Breen et al., 2017).

SnToxA was shown to interact with wheat's PR-1-5, while SnTox3 was shown to interact with PR-1-1 as well as six other members from the PR-1 family (Breen et al., 2017). It has been identified that PR-1-derived defense signaling peptide from the C-terminus of TaPR-1-1, known as CAPE1, falls within the proposed SnTox3-TaPR-1 interaction surface and enhances the infection of wheat by S. nodorum in an SnTox3-dependent manner, but plays no role in SnToxA-mediated disease (Breen et al., 2017). This result indicates that CAPE1 may play an important role in the signal transduction pathway leading to disease for SnTox3 but not SnToxA. Nevertheless, it remains unknown how SnTox3 uses TaCAPE1 for this function and what role $\operatorname{Snn} 3$ plays in the interaction.

Certainly, many more questions await answers. How is CAPE1 cleaved from PR-1 proteins? Could SnTox3 induce the cleavage of the TaCAPE1 peptide? What pathways act downstream of CAPE1 detection and/or accumulation? It is clear that both PR-1 proteins and CAPE1 peptides are important host defense molecules.

Our results showed that suppression of defense responses and development of large lesions in susceptible wheat genotypes was associated with inhibition of the marker genes for transcription of the SA-signaling pathway, $P R-1$ and $P R-2$, at 
the initial stage of infection (Veselova et al., 2016). In addition, it was proved that it was ethylene that suppressed the induction of SA-dependent defense response (Veselova et al., 2016).

\section{Conclusions}

Much progress has been made in describing and understanding the wheat-S. nodorum system over the past two decades. It is known that the fungus produces NEs, which, when recognized by specific host sensitivity genes, induce disease, and that these host-NEs relationships follow an inverse gene-for-gene model. However, the mechanisms of the interaction of wheat and $S$. nodorum is very complicated, race specific interaction explaining only $40 \%$ of phenotypic expression (Faris et al., 2013; Shi et al., 2016; McDonald, Solomon, 2018). It is known that race non-specific QTLs that confer broad-spectrum - and potentially durable - resistance exist. The genetic basis of host resistance to $S$. nodorum in seedlings and adult plants is complex. SNB resistance has been reported to be quantitatively inherited in some instances (race-nonspecific resistance) and qualitatively inherited in others (race-specific gene-for-gene resistance). Resistance to this pathogen is controlled by a variety of mechanisms and, accordingly, a variety of genes. Therefore, the wheat- $S$. nodorum system is much more complex than currently described in the literature, and much additional work is needed to characterize this pathosystem.

Furthermore, relatively recently, over the past four years, the interaction of SnTox-Snn causing susceptibility has been shown to be targeted to manipulation of non-specific pathways of plant protection associated with redox-metabolism, secondary metabolites and pathogenesis-related proteins (Liu et al., 2012; Winterberg et al., 2014; McDonald, Solomon, 2018; Veselova et al., 2018a; b).

More work to identify and characterize race non-specific resistance QTLs will also be useful. The molecular cloning of more NE sensitivity genes and race non-specific resistance QTLs will allow further characterization of wheat-S. nodorum interactions, and shed light on the relationship between hostNEs interactions and race non-specific resistance mechanisms at the molecular level. It will also provide the tools necessary for the development of functional markers, which can be used to conduct highly efficient MAS for the pyramiding of NE insensitivity genes together with race non-specific resistance loci leading to the development of wheat with superior SNB resistance.

\section{References}

Breen S., Williams S.J., Outram M., Kobe B., Solomon P.S. Emerging insights into the functions of Pathogenesis-Related Protein 1. Trends Plant Sci. 2017;22(10):872-879. doi.org/10.1016/j.tplants. 2017.06.013.
Fall L.A., Solomon P.S. The necrotrophic effector SnToxA induces the synthesis of a novel phytoalexin in wheat. New Phytologist. 2013;200:185-200. DOI 10.1111/nph.12356.

Faris J.D. Liu Z., Xu S.S. Genetics of tan spot resistance in wheat. Theor Appl Genet. 2013;126:2197-2217. DOI 10.1007/s00122-0132157-y.

Liu Z., Zhang Z., Faris J.D., Oliver R.P., Syme R., McDonald M.C., McDonald B.A., Solomon P.S., Lu S., Shelver W.L., Xu S., Friesen T.L. The cysteine rich necrotrophic effector SnTox 1 produced by Stagonospora nodorum triggers susceptibility of wheat lines harboring Snn1. PLoS Pathog. 2012;8(1):e1002467. DOI 10.1371/journal. ppat.1002467.

McDonald M.C., Solomon P.S. Just the surface: advances in the discovery and characterization of necrotrophic wheat effectors. Current Opinion Microbiol. 2018;46:14-18. doi.org/10.1016/j.mib.2018. 01.019

Oliver R.P., Friesen T.L., Faris J.D., Solomon P.S. Stagonospora nodorum : from pathology to genomics and host resistance. Annu. Rev. Phytopathol. 2012;50:23-43. DOI 10.1146/annurev-phyto-081211173019.

Phan H.T.T., Rybak K., Furuki E., Breen S., Solomon P.S., Oliver R.P., Tan K.-C. Differential effector gene expression underpins epistasis in a plant fungal disease. Plant Journal. 2016;87:343-354.

Shi G., Zhang Z., Friesen T.L., Raats D., Fahima T., Brueggeman R.S., Lu S., Trick H.N., Liu Z., Chao W., Frenkel Z., Xu S.S., Rasmussen J.B., Faris J.D., The hijacking of a receptor kinase-driven pathway by a wheat fungal pathogen leads to disease. Sci. $A d v .2016$; 2(10):e1600822. DOI 10.1126/sciadv.1600822.

Veselova S.V., Burkhanova G.F. Ethylene and mitogenactivated protein kinases in regulation of redoxstatus in common wheat infected with Stagonospora nodorum. Ecobiotech. J. 2018a;1(4):201-215. DOI 10.31163/2618-964X-2018-1-4-201-215. (in Russian)

Veselova S.V., Burkhanova G.F., Maksimov I.V. Effect of phytopathogenic fungus Septoria nodorum Tox3 effector on the pro-/antioxidant status of wheat plants. Materials of the international symposium molecular aspects of plant redox metabolism. 2017;87-92 (in Russian)

Veselova S.V., Burkhanova G.F., Nuzhnaya T.V., Maksimov I.V. Roles of ethylene and cytokinins in development of defense responses in Triticum aestivum plants infected with Septoria nodorum. Russian J Plant Physiol. 2016;63(5):609-619. DOI 10.1134/ S1021443716050150.

Veselova S.V., Burkhanova G.F., Nuzhnaya T.V., Rumyantsev S.D., Maksimov I.V. Influence of ethylene and reactive oxygen species on the growth of the pathogen Stagonospora nodorum Berk. in wheat plant tissue. Biomics. 2018b;10(4):387-399. DOI 10.31301/22216197.bmcs.2018-50. (in Russian)

Winterberg B., Du Fall L.A., Song X., Pascovici D., Care N., Molloy M., Ohms S., Solomon P.S. The necrotrophic effector protein SnTox3 re-programs metabolism and elicits a strong defence response in susceptible wheat leaves. BMC Plant Biol. 2014;14:215. DOI 10.1186/s12870-014-0215-5.

Acknowledgements: The work was supported by the Russian Foundation for Basic Research (project no. 18-04-00978).

Conflict of interest. The authors declare no conflict of interest. 